\title{
Anxiety and harmful oral habits in preschool children during the 2020 first-wave COVID-19 lockdown in Turkey
}

\author{
Kevser Kolcakoglu ${ }^{A-F}$, Gul Yucel ${ }^{A-C, E}$ \\ Department of Pediatric Dentistry, Faculty of Dentistry, Erciyes University, Kayseri, Turkey \\ A - research concept and design; $\mathrm{B}$ - collection and/or assembly of data; $\mathrm{C}$ - data analysis and interpretation; \\ $D$ - writing the article; $E$ - critical revision of the article; $F$ - final approval of the article
}

\section{Address for correspondence \\ Kevser Kolcakoglu}

E-mail: kevser.kolcakoglu@gmail.com

Funding sources

None declared

Conflict of interest

None declared

Acknowledgements

The authors would like to thank the psychologist Görkem Güler.

Received on July 19, 2021

Reviewed on September 8, 2021

Accepted on September 15, 2021

Published online on December 20, 2021

\begin{abstract}
Background. Due to curfew and quarantine practices designed to reduce the spread of coronavirus disease 2019 (COVID-19), social isolation has tested the psychological limits of children.

Objectives. The authors evaluated parent-observed symptoms of anxiety in preschool children with harmful oral habits during the curfew period in Turkey.

Material and methods. The authors prepared a questionnaire with Google Forms that was distributed through social media applications (e.g., WhatsApp) to 405 parents recruited via snowball sampling. To measure children's symptoms and levels of anxiety, the Spence Preschool Anxiety Scale (SPAS) was used. Harmful oral habits that might develop in children during the curfew were investigated.

Results. Separation anxiety and physical injury anxiety were reported by the parents more frequently than general anxiety and obsessive-compulsive disorder. Also, the presence of tantrums $(p=0.010)$, crying attacks $(p=0.010)$ and aggression $(p=0.010)$ were reported by the parents in these children. It was observed that the habits of finger sucking $(p=0.010)$, nail biting $(p=0.040)$ and lip biting $(p=0.010)$ that were present before the curfew decreased significantly after the curfew.

Conclusions. Children aged 3-7 years can develop anxiety about physical injuries and about being separated from their parents as well as tantrums and crying attacks. Their harmful oral habits (i.e., finger sucking, nail biting and lip biting) all decreased during the curfew period.
\end{abstract}

Keywords: children, aggression, finger sucking, nail biting, separation anxiety disorder

Cite as

Kolcakoglu K, Yucel G. Anxiety and harmful oral habits

in preschool children during the 2020 first-wave COVID-19

lockdown in Turkey. Dent Med Probl. 2021;58(4):433-439.

doi:10.17219/dmp/142284

DOI

$10.17219 / \mathrm{dmp} / 142284$

Copyright

C 2021 by Wroclaw Medical University

This is an article distributed under the terms of the

Creative Commons Attribution 3.0 Unported License (CC BY 3.0)

(https://creativecommons.org/licenses/by/3.0/) 


\section{Introduction}

Coronaviruses $(\mathrm{CoV})$ are a family of viruses that can cause illnesses ranging from severe respiratory infections to mild conditions, like the common cold. In January 2020, a novel coronavirus, 2019-nCoV, began causing cases of pneumonia in Wuhan, China. ${ }^{1}$ The virus was similar to severe acute respiratory syndrome coronavirus (SARS-CoV), but had never been detected in humans before.

On March 11, 2020, following the spread of coronavirus disease 2019 (COVID-19) in 113 countries, including Turkey, the World Health Organization (WHO) declared COVID-19 a pandemic. Since the first infection with the virus diagnosed in humans until August 16, 2020, approx. 21.2 million cases and 761,000 deaths were reported worldwide. ${ }^{1}$ For those and other reasons, COVID-19 has been perceived as a major threat not only to public health, but also to the global economy.

Health authorities in Turkey and other countries have advised canceling conferences, ceremonies, and various art and cultural events, suspending educational activities, imposing bans on domestic and international air travelling, and initiating quarantine practices to reduce the spread of the virus. In Turkey, to mitigate the risks posed to public health by curbing people's interpersonal contact and social mobility, the government implemented a curfew prohibiting children aged $<20$ years from being in public places between April 3, 2020 and June 1, 2020. ${ }^{2}$ Such practices to control the spread of COVID-19 in Turkey significantly altered daily routines by requiring long-term periods spent at home, eliminating direct contact with friends and, in turn, causing boredom, and even familial behavioral problems, which psychologically challenge children as much as adults. ${ }^{2-5}$ Regarding children in particular, studies have shown that those who are more stressed move less, spend more time in front of the television or computer, and consume less healthy foods, especially on weekends or during summer holidays, when not attending school., ${ }^{2,6,7}$ Beyond that, their fear of asking questions about the pandemic and the health of relatives, poor sleep, including nightmares, poor appetite, physical discomfort, agitation, inattention, and separation problems may prompt the development of psychological disorders in children. ${ }^{3}$ Such disorders in children may promote harmful oral habits or change the existing good habits. ${ }^{5,8-10}$

The authors aimed to evaluate the symptoms of anxiety observed by parents in their 3-7-year-old children, and assess the children's harmful oral habits before and after the 2 months of Turkey's curfew.

\section{Subjects and methods}

This study received ethical approval from the Clinical Research Ethics Committee at the Faculty of Medicine of Erciyes University, Kayseri, Turkey (No. 352-2020).

\section{Setting and participants}

To prevent the spread of COVID-19 and avoid overburdening the healthcare system, the Turkish government has promoted the reduction of face-to-face interviews since spring 2020. For that reason, the consent form and the questionnaire, developed in compliance with the Declaration of Helsinki, were created with Google Forms and distributed through social media applications (e.g., WhatsApp) to parents recruited via snowball sampling by providing access to https://docs.google.com/forms/d/ 12n1QnyRH9LW6wpfrFtN7jscb2m1rkKDjoVdIU5mW $8 \mathrm{Hc}$ /edit. A total of 783 questionnaires were completed; however, 147 forms were excluded because of children and parents having mental and systemic diseases. Also, 231 forms were excluded due to children who were over 7 years old. Ultimately, 405 questionnaires were included in this study.

\section{Questionnaire content}

The $1^{\text {st }}$ questionnaire was sent to the participants in the $1^{\text {st }}$ week of April 2020 to evaluate harmful oral habits, and the $2^{\text {nd }}$ questionnaire was sent to the same e-mail addresses in the $2^{\text {nd }}$ week of June 2020 to re-evaluate harmful oral habits, determine the Spence Preschool Anxiety Scale (SPAS) scores and assess different behavioral problems.

The questionnaire consisted of 5 parts.

The $1^{\text {st }}$ part asked the participating parents questions about their own and their children's demographic information, including their age, gender, level of education, their children's age, and family structure (e.g., the number of children).

The $2^{\text {nd }}$ part of the questionnaire incorporated SPAS. The parents answered questions listed under "General anxiety", "Obsessive-compulsive disorder", "Separation anxiety", and "Physical injury anxiety" on a 5-point Likert scale from 0 ('not true at all') to 4 ('very often true'). However, the parents did not answer questions listed under "Social anxiety" due to their irrelevance amid the curfew.

The $3^{\text {rd }}$ part asked the parents questions about different symptoms of anxiety observed in their children, namely tantrums, crying attacks and aggression, to be answered with either 0 (absent) or 1 (present). The authors sought a yes or no answer to whether behavioral symptoms developed during the period from the beginning to the end of the curfew.

The $4^{\text {th }}$ part asked whether the children demonstrated any harmful oral habits, namely finger sucking, nail biting and lip biting, before the curfew. A 4-point scale referring to the frequency of harmful habit episodes ( 0 = 'none'; 1 = 'few'; 2 = 'some'; 3 = 'many') was used.

In a follow-up, using the same scale, the $5^{\text {th }}$ and final part of the questionnaire asked whether the children demonstrated the same habits after the curfew had ended. 


\section{Statistical analysis}

The authors analyzed the data with the IBM SPSS Statistics for Windows software, v. 23.0 (IBM Corp., Armonk, USA). In particular, the authors used the independent samples $t$ test to compare the anxiety scores according to different symptoms of anxiety, the McNemar-Bowker test to examine any changes in the frequency of harmful oral habits, and the $t$ test to examine changes in the presence of harmful oral habits before and after the curfew. The one-sample $t$ test analysis was carried out to analyze differences between the anxiety levels obtained in the present study and the mean scores reported in the norm study. ${ }^{11}$ The post hoc Šídák pairwise comparison test was performed to determine whether the values obtained for the anxiety subdimensions in the present study were statistically significantly different or not, and to rank the values of the anxiety subdimensions. Categorical data was recorded as number $(n)$ and percentage (\%), and quantitative data as mean $(M)$ and standard deviation $(S D)$. Any $p$-value $<0.05$ was considered to indicate statistical significance.

\section{Results}

There were 405 parents who responded to the questionnaire and were included in the analysis. Their mean age was 33.8 years, and by gender, $92.8 \%$ were women and $7.2 \%$ were men. By level of education, $19.8 \%$ of the respondents had graduated from high school, $62.0 \%$ from university and 9.9\% from doctoral studies. The children's mean age was 5.1 years. The children of a significant majority of the respondents $(83.5 \%)$ were attending preschool and the children of as many as $68.4 \%$ of the respondents had at least 1 sibling (Table 1 ).

As mentioned, the questions on SPAS address 5 types of anxiety: general anxiety (i.e., Q1, Q4, Q8, Q14, and Q28); obsessive-compulsive disorder (i.e., Q3, Q9, Q18, Q21, and Q27); separation anxiety (i.e., Q6, Q12, Q16, Q22, and Q25); physical injury anxiety (i.e., Q7, Q10, Q13, Q17, Q20, Q24, and Q26); and social anxiety (i.e., Q2, Q5, Q11, Q15, Q19, and Q23). The questions listed under "Social anxiety" were not answered due to their irrelevance amid the curfew. Along those lines, separation anxiety and physical injury anxiety were reported relatively often among the children (Table 2).

It was found that there was a significant difference between the general anxiety levels of the participants in the present study and those obtained in the norm study, with the latter ones being higher $(p=0.010)$. It was found that there was a significant difference between the obsessivecompulsive disorder levels of the participants in the present study and those obtained in the norm study, with the latter ones again being higher $(p=0.010)$. It was observed that there was a significant difference between the physical
Table 1. Demographic data of the respondents

\begin{tabular}{|c|c|c|}
\hline \multicolumn{2}{|c|}{ Demographic data } & $\begin{array}{c}M \pm S D \\
95 \% C I(\min -\max ) \\
\text { or } \\
n(\%)\end{array}$ \\
\hline \multicolumn{2}{|l|}{ Parent's age [years] } & $\begin{array}{c}33.8 \pm 4.8 \\
33.0(20.0-45.0)\end{array}$ \\
\hline \multicolumn{2}{|l|}{ Children's age [years] } & $\begin{array}{c}5.1 \pm 1.2 \\
5.0(0.6-7.0)\end{array}$ \\
\hline \multirow{2}{*}{ Parent's gender } & female & $376(92.8)$ \\
\hline & male & $29(7.2)$ \\
\hline \multirow{4}{*}{$\begin{array}{l}\text { What is your } \\
\text { educational } \\
\text { background? }\end{array}$} & university & $251(62.0)$ \\
\hline & high school & $80(19.8)$ \\
\hline & doctorate/expertise & $40(9.9)$ \\
\hline & other & $34(8.4)$ \\
\hline \multirow{2}{*}{$\begin{array}{l}\text { Does your child go } \\
\text { to preschool? }\end{array}$} & yes & $338(83.5)$ \\
\hline & no & $67(16.5)$ \\
\hline \multirow{2}{*}{$\begin{array}{l}\text { Does your child have } \\
\text { a sibling? }\end{array}$} & yes & 277 (68.4) \\
\hline & no & $128(31.6)$ \\
\hline \multirow{2}{*}{ Family type } & nuclear & $366(90.4)$ \\
\hline & extended & $39(9.6)$ \\
\hline
\end{tabular}

M - mean; SD - standard deviation; $\mathrm{Cl}$ - confidence interval;

min - minimum; max - maximum; $n$ - number; $\%$ - percentage.

injury anxiety levels of the participants in the current study and those obtained in the norm study, which were lower in this case $(p=0.010)$. Finally, it was observed that there was a significant difference between the separation anxiety levels of the participants in the current study and those obtained in the norm study, which were again lower $(p=0.010)$ (Table 3).

It was found that the mean scores for general anxiety, obsessive-compulsive disorder, physical injury anxiety, and separation anxiety were significantly different $(p=0.010)$; it was due to the higher levels of physical injury anxiety and separation anxiety as compared to other anxiety subdimensions $(p=0.010 ; p<0.05)$ (Table 4$)$.

Regarding the examined symptoms of anxiety (i.e., tantrums, crying attacks and aggression), the frequency of tantrums was $28.6 \%$, of crying attacks $-32.8 \%$ and of aggression (i.e., self-hitting and hitting others) - $26.7 \%$ (Table 5). The children with higher SPAS scores had more tantrums $(p=0.010)$. The same correlation occurred in the case of crying attacks $(p=0.010)$ and aggression $(p=0.010)$ (Table 6).

It was observed that the finger sucking habit observed in the children before the curfew decreased significantly after the curfew $(p=0.010)$. Similarly, significant decreases where observed after the curfew in the nail biting habit $(p=0.040)$ and in the lip biting habit $(p=0.010)$ as compared to the situation before the curfew (Table 7). In particular, 99.2\% of the children did not suck their fingers before the curfew, nor did they afterward, whereas $66.7 \%$ with few finger sucking episodes before the curfew kept their habit at the same level afteward. 
Table 2. Spence Preschool Anxiety Scale (SPAS) scores

\begin{tabular}{|c|c|c|c|c|c|c|}
\hline \multirow{2}{*}{$\begin{array}{c}\text { Anxiety } \\
\text { subdimension }\end{array}$} & \multirow{2}{*}{$\begin{array}{c}\text { SPAS } \\
\text { questions }\end{array}$} & \multicolumn{5}{|c|}{ SPAS answers } \\
\hline & & not true at all & seldom true & sometimes true & quite often true & very often true \\
\hline \multirow{5}{*}{ General anxiety } & Q1 & $112(27.7)$ & $120(29.6)$ & $100(24.7)$ & $59(14.6)$ & $14(3.5)$ \\
\hline & Q4 & $124(30.6)$ & $148(36.5)$ & $69(17.0)$ & $48(11.9)$ & $16(4.0)$ \\
\hline & Q8 & $166(41.0)$ & $122(30.1)$ & $58(14.3)$ & $41(10.1)$ & $18(4.4)$ \\
\hline & Q14 & $264(65.2)$ & $85(21.0)$ & $32(7.9)$ & $9(2.2)$ & $15(3.7)$ \\
\hline & Q28 & $246(60.7)$ & $85(21.0)$ & $38(9.4)$ & $21(5.2)$ & $15(3.7)$ \\
\hline \multirow{5}{*}{$\begin{array}{l}\text { Obsessive-compulsive } \\
\text { disorder }\end{array}$} & Q3 & $178(44.0)$ & $107(26.4)$ & $61(15.1)$ & $37(9.1)$ & $22(5.4)$ \\
\hline & Q9 & $186(45.9)$ & $90(22.2)$ & 55 (13.6) & $34(8.4)$ & $40(9.9)$ \\
\hline & Q18 & $221(54.6)$ & $82(20.2)$ & $48(11.9)$ & $22(5.4)$ & $32(7.9)$ \\
\hline & Q21 & $223(55.1)$ & $97(24.0)$ & $43(10.6)$ & $27(6.7)$ & $15(3.7)$ \\
\hline & Q27 & $293(72.3)$ & $53(13.1)$ & $29(7.2)$ & $11(2.7)$ & $19(4.7)$ \\
\hline \multirow{5}{*}{ Separation anxiety } & Q6 & $81(20.0)$ & $73(18.0)$ & $56(13.8)$ & $87(21.5)$ & $108(26.7)$ \\
\hline & Q12 & $115(28.4)$ & $112(27.7)$ & $85(21.0)$ & $44(10.9)$ & $49(12.1)$ \\
\hline & Q16 & $173(42.7)$ & $127(31.4)$ & $43(10.6)$ & $24(5.9)$ & $38(9.4)$ \\
\hline & Q22 & $186(45.9)$ & $99(24.4)$ & $44(10.8)$ & $36(8.8)$ & $40(9.8)$ \\
\hline & Q25 & $235(58.0)$ & $91(22.5)$ & $43(10.6)$ & $26(6.4)$ & $10(2.5)$ \\
\hline \multirow{7}{*}{ Physical injury anxiety } & Q7 & $134(33.1)$ & $92(22.7)$ & $69(17.0)$ & $50(12.3)$ & $60(14.8)$ \\
\hline & Q10 & $220(54.3)$ & $86(21.2)$ & $49(12.1)$ & $28(6.9)$ & $22(5.4)$ \\
\hline & Q13 & $122(30.1)$ & $130(32.1)$ & $63(15.6)$ & $51(12.6)$ & $39(9.6)$ \\
\hline & Q17 & $152(37.5)$ & $80(19.8)$ & $71(17.5)$ & $53(13.1)$ & $49(12.1)$ \\
\hline & Q20 & 109 (26.9) & $108(26.7)$ & $76(18.8)$ & $49(12.1)$ & $63(15.6)$ \\
\hline & Q24 & $205(50.6)$ & $96(23.7)$ & $45(11.1)$ & $34(8.4)$ & $25(6.2)$ \\
\hline & Q26 & $80(19.8)$ & $126(31.1)$ & $70(17.3)$ & $61(15.1)$ & $68(16.8)$ \\
\hline \multirow{6}{*}{ Social anxiety } & Q2 & - & - & - & - & - \\
\hline & Q5 & - & - & - & - & - \\
\hline & Q11 & - & - & - & - & - \\
\hline & Q15 & - & - & - & - & - \\
\hline & Q19 & - & - & - & - & - \\
\hline & Q23 & - & - & - & - & - \\
\hline
\end{tabular}

Table 3. Evaluation of the anxiety subdimensions with regard to the norm study ${ }^{11}$

\begin{tabular}{|l|c|c|c|}
\multicolumn{1}{|c|}{ Anxiety } & \multicolumn{1}{|c|}{$\begin{array}{c}\text { Present study } \\
\text { subdimension }\end{array}$} & $\begin{array}{c}\text { Norm study } \\
(N=405)\end{array}$ & $p$-value \\
\hline $\begin{array}{l}\text { General anxiety } \\
\text { Obsessive-compulsive } \\
\text { disorder }\end{array}$ & $9.54 \pm 4.33^{\mathrm{a}}$ & $14.93 \pm 3.67^{\mathrm{b}}$ & $0.010^{*}$ \\
$\begin{array}{l}\text { Physical injury } \\
\text { anxiety }\end{array}$ & $16.20 \pm 5.37^{\mathrm{b}}$ & $9.61 \pm 3.17^{\mathrm{a}}$ & $0.010^{*}$ \\
$\begin{array}{l}\text { Separation anxiety } \\
\text { Total SPAS score }\end{array}$ & $17.92 \pm 4.41^{\mathrm{b}}$ & $12.72 \pm 4.07^{\mathrm{a}}$ & $0.010^{*}$ \\
\hline
\end{tabular}

Data presented as $M \pm S D$. SPAS - Spence Preschool Anxiety Scale; ${ }^{\dagger}$ one-sample $t$ test; ${ }^{*}$ statistically significant $(\mathrm{a}<\mathrm{b})$.

Table 5. Frequency of behavioral problems

\begin{tabular}{|l|c|c|}
\hline \multicolumn{1}{|c|}{ Behavioral problem } & Absent & Present \\
\hline Tantrums & $289(71.4)$ & $116(28.6)$ \\
Crying attacks & $272(67.2)$ & $133(32.8)$ \\
Aggression & $297(73.3)$ & $108(26.7)$ \\
\hline
\end{tabular}

Data presented as $n(\%)$.
Table 4. Analysis of differences between the anxiety subdimensions in terms of the Spence Preschool Anxiety Scale (SPAS) scores

\begin{tabular}{|c|c|c|c|}
\hline Anxiety subdimension & $M \pm S D$ & $p$-value ${ }^{\dagger}$ & $\begin{array}{l}\text { Post hoc } \\
\text { test result }\end{array}$ \\
\hline General anxiety & $10.10 \pm 3.92$ & \multirow{4}{*}{$0.010^{*}$} & \multirow{4}{*}{$\begin{array}{c}3.4>1.2 \\
\left(p<0.05^{*}\right)\end{array}$} \\
\hline $\begin{array}{l}\text { Obsessive-compulsive } \\
\text { disorder }\end{array}$ & $9.54 \pm 4.33$ & & \\
\hline Physical injury anxiety & $16.20 \pm 5.37$ & & \\
\hline Separation anxiety & $17.92 \pm 4.41$ & & \\
\hline
\end{tabular}

† post hoc Šídák pairwise comparison test; * statistically significant.

Table 6. Presence of behavioral problems according to the Spence Preschool Anxiety Scale (SPAS) scores

\begin{tabular}{|l|c|c|c|}
\hline Behavioral problem & Absent & Present & $p_{\text {-value }}$ \\
\hline Tantrums & $52.27 \pm 16.29$ & $57.11 \pm 17.75$ & $0.010^{*}$ \\
Crying attacks & $52.68 \pm 13.49$ & $55.82 \pm 17.46$ & $0.010^{*}$ \\
Aggression & $51.97 \pm 15.89$ & $58.63 \pm 16.57$ & $0.010^{*}$ \\
\hline
\end{tabular}

Data presented as $M \pm S D .{ }^{\dagger}$ independent samples $t$ test; ${ }^{*}$ statistically significant. 
By contrast, $33.3 \%$ of the same group stopped finger sucking altogether. While $28.6 \%$ of the children who were observed to suck their fingers moderately before the curfew stopped finger sucking, $28.6 \%$ of them continued to suck a little and $42.9 \%$ of them did not alter the frequency of the habit. Trends in nail biting, however, differed from those in finger sucking. While $23.9 \%$ of the children who bit their nails before the curfew stopped biting their nails afterward, $71.6 \%$ continued to bite their nails, but not often, and $3.0 \%$ were reported to bite their nails at a moderate frequency. Finally, lip biting also differed after vs. before social isolation (Table 8).

\section{Discussion}

Staying at home can facilitate the improvement of social relations between family members, and such close relationships between children and the rest of the family can prevent physical and psychological problems that may otherwise develop. ${ }^{12}$ However, owing to a prevalent life-threatening illness, children's levels

Table 7. Changes in the presence of harmful oral habits before and after the curfew

\begin{tabular}{|c|c|c|c|}
\hline Harmful oral habit & Evaluation time & Absent & $p$-value ${ }^{\dagger}$ \\
\hline \multirow{2}{*}{ Finger sucking } & before the curfew & $0.14 \pm 0.51$ & \multirow{2}{*}{$0.010^{*}$} \\
\hline & after the curfew & $0.10 \pm 0.41$ & \\
\hline \multirow{2}{*}{ Nail biting } & before the curfew & $0.42 \pm 0.78$ & \multirow{2}{*}{$0.040^{*}$} \\
\hline & after the curfew & $0.38 \pm 0.77$ & \\
\hline \multirow{2}{*}{ Lip biting } & before the curfew & $0.19 \pm 0.53$ & \multirow{2}{*}{$0.010^{*}$} \\
\hline & after the curfew & $0.15 \pm 0.48$ & \\
\hline \multirow{2}{*}{ Total } & before the curfew & $0.76 \pm 1.28$ & \multirow{2}{*}{$0.010^{*}$} \\
\hline & after the curfew & $0.62 \pm 0.74$ & \\
\hline
\end{tabular}

Data presented as $M \pm S D .{ }^{\dagger} t$ test; ${ }^{*}$ statistically significant. of anxiety and stress while at home may rise. ${ }^{8}$ Anxiety is defined as a feeling of powerlessness, fear and discontent in a seemingly threatening environment. ${ }^{13}$ If children's anxiety can be appropriately controlled by their families, then they can overcome the condition of distress and become stable, both emotionally and physiologically, even in social isolation during a pandemic such as COVID-19. ${ }^{14}$ Considering that possibility, the authors evaluated the anxiety observed by parents in their 3-7-year-old children in social isolation during Turkey's 2-month curfew. To that purpose, the authors used SPAS, which has been validated for Turkish children and the reliability of which has been confirmed. ${ }^{11,15}$ The questionnaire was administered using the snowball technique through WhatsApp and other social media applications. The questionnaire addressed 5 types of anxiety on a Likert-type scale, but social anxiety questions were not included. The reason why the social anxiety questions were not answered is the "stay at home" and "curfew restriction under the age of 20" practices. Therefore, it was not possible to statistically compare the before and after scores on the same SPAS questionnaire. Hence, the authors compared the SPAS anxiety scores obtained in the present study with the norm values specified for Turkish preschool children. ${ }^{11}$ In the present study, although the general anxiety and obsessive-compulsive disorder data was found to be lower than the norm values, the total SPAS anxiety scores were found to be higher than in the norm study. This difference was due to the higher levels of separation anxiety and physical injury anxiety observed in the present study.

Earlier research, which did not indicate the age range, found that quarantine practices could lead to the development of separation anxiety as well as a fear of infection in children, which in the long term might affect a child's mental health. ${ }^{4}$ Added to that, Spence et al. posited that

Table 8. Changes in the frequency of harmful oral habits before and after the curfew (McNemar-Bowker test)

\begin{tabular}{|c|c|c|c|c|c|}
\hline \multirow{2}{*}{ Harmful oral habit } & \multirow{2}{*}{ Before the curfew } & \multicolumn{4}{|c|}{ After the curfew } \\
\hline & & none & few & some & many \\
\hline \multirow{4}{*}{ Finger sucking } & none & $368(99.2)$ & $2(0.5)$ & $0(0.0)$ & $1(0.3)$ \\
\hline & few & $5(33.3)$ & $10(66.7)$ & $0(0.0)$ & $0(0.0)$ \\
\hline & some & $4(28.6)$ & $4(28.6)$ & $6(42.9)$ & $0(0.0)$ \\
\hline & many & $0(0.0)$ & $2(40.0)$ & $1(20.0)$ & $2(40.0)$ \\
\hline \multirow{4}{*}{ Nail biting } & none & $284(96.3)$ & $11(3.7)$ & $0(0.0)$ & $0(0.0)$ \\
\hline & few & $16(23.9)$ & $48(71.6)$ & $2(3.0)$ & $1(1.5)$ \\
\hline & some & $4(14.8)$ & $4(14.8)$ & $14(51.9)$ & $5(18.5)$ \\
\hline & many & $2(12.5)$ & $0(0.0)$ & $0(0.0)$ & $14(87.5)$ \\
\hline \multirow{4}{*}{ Lip biting } & none & $345(98.9)$ & $3(0.9)$ & $0(0.0)$ & $1(0.3)$ \\
\hline & few & $20(45.5)$ & $23(52.3)$ & $1(2.3)$ & $0(0.0)$ \\
\hline & some & $1(16.7)$ & $1(16.7)$ & $3(50.0)$ & $1(16.7)$ \\
\hline & many & $1(16.7)$ & $0(0.0)$ & $2(33.3)$ & $3(50.0)$ \\
\hline
\end{tabular}

Data presented as n (\%). 
separation anxiety and physical injury anxiety were common in preschool children, ${ }^{16}$ while Edwards et al. observed children's fear of physical injury marked by a fear of darkness, disease and specific animals. ${ }^{17}$ Consistent with those results, the authors of the present study reported that separation anxiety and physical injury anxiety were the most common trends in the respondents' children aged 3-7 years. Consequently, communication among family members is pivotal in controlling not only the spread of the infection, but also separation anxiety. ${ }^{8}$ In communication with children aged 3-7 years, it is necessary to use concrete language in order to avoid misunderstanding.

In research on the emotional and behavioral changes in children during COVID-19, Jiao et al. found that anxiety increased in children aged 3 months -17 years during the COVID-19 pandemic, ${ }^{18}$ while Pisano et al. observed that children aged 4-10 years in the same situation had trouble sleeping and exhibited sudden emotional changes. ${ }^{19}$ In the present study, the authors also investigated behavioral problems, such as tantrums, crying attacks and aggression, among children during Turkey's curfew. Since behaviors are generally acquired from what individuals observe in their environments or during social learning, behavioral problems can occur in preschool children due to the effects of environmental factors. ${ }^{20}$ Examinations of children aged 3-7 years and adolescents in groups have revealed that parental attitudes and behaviors appear to be important factors in determining children's and adolescents' positive social behaviors. $^{21}$ The results of this study showed that the frequency of tantrums, crying attacks and aggressive behaviors increased significantly after the curfew. The authors of the present study believe that increases in separation anxiety and physical injury anxiety might have increased the frequency of tantrums and crying attacks. In the current study, the frequency of finger sucking, lip biting and nail biting decreased significantly during the curfew. In general, anxiety, fear, tension, and jealousy can damage children's sense of trust in their parents, and prompt finger sucking, nail biting and lip biting due to the feeling of deprivation. ${ }^{22}$ These parafunctional oral habits are harmful, as they can directly affect the growth and development of the oral and maxillofacial skeleton. In addition, malocclusion can occur. ${ }^{10,23,24}$ Although research on children with anxiety is likely to report harmful oral habits, ${ }^{25,26}$ this study found that such harmful oral habits as finger sucking, lip biting and nail biting decreased significantly during the curfew. The occurrence of harmful oral habits may originate as an emotional need. ${ }^{27}$ Although the authors do not know how children spent time with their parents during social isolation, the reason for decreases in harmful oral habits might be a sense of trust between parents and children. Spending time together helps to develop a sense of trust in the family, which may prevent harmful oral habits, and thereby prevent malocclusion. ${ }^{28}$

\section{Limitations}

One limitation of this study is that the SPAS scores at the beginning of the social isolation period could not be obtained, as the social anxiety questions had not been answered by parents due to the curfew. The study aimed to investigate the effects of social isolation on children's harmful oral habits, and their anxiety levels and symptoms instead of explaining the reasons for the related changes. Further studies are warranted to evaluate the amount of screen time or time spent on other activities by children during isolation, alone or with their parents, to clarify the possible reasons for changes in oral habits as well as anxiety levels and symptoms.

\section{Conclusions}

Children aged 3-7 years who cannot attend school, or sufficiently participate in social and physical activities can develop anxiety about suffering physical injuries and becoming separated from their parents. At the same time, this study showed that tantrums and crying attacks increased, while harmful oral habits (i.e., finger sucking, nail biting and lip biting) all decreased in children during Turkey's curfew.

\section{ORCID iDs}

Kevser Kolcakoglu (1) https://orcid.org/0000-0003-2596-8678 Gul Yucel (1) https://orcid.org/0000-0001-7152-1127

\section{References}

1. Khan M, Adil SF, Alkhathlan HZ, et al. COVID-19: A global challenge with old history, epidemiology and progress so far. Molecules. 2020;26(1):39. doi:10.3390/molecules26010039

2. Demirbilek Y, Pehlivantürk G, Özgüler ZÖ, Meşe EA. COVID-19 outbreak control, example of Ministry of Health of Turkey. Turk J Med Sci. 2020;50(SI-1):489-494. doi:10.3906/sag-2004-187

3. Brooks SK, Webster RK, Smith LE, et al. The psychological impact of quarantine and how to reduce it: Rapid review of the evidence. Lancet. 2020;395(10227):912-920. doi:10.1016/S0140-6736(20)30460-8

4. Liu JJ, Bao Y, Huang X, Shi J, Lu L. Mental health considerations for children quarantined because of COVID-19. Lancet Child Adolesc Health. 2020;4(5):347-349. doi:10.1016/S2352-4642(20)30096-1

5. Wang G, Zhang Y, Zhao J, Zhang J, Jiang F. Mitigate the effects of home confinement on children during the COVID-19 outbreak. Lancet. 2020;395(10228):945-947. doi:10.1016/S0140 6736(20)30547-X

6. Choi EPH, Hui BPH, Wan EYF. Depression and anxiety in Hong Kong during COVID-19. Int J Environ Res Public Health. 2020;17(10):3740. doi:10.3390/ijerph17103740

7. Wang G, Zhang J, Lam SP, et al. Ten-year secular trends in sleep/ wake patterns in Shanghai and Hong Kong school-aged children: A tale of two cities. J Clin Sleep Med. 2019;15(10):1495-1502. doi:10.5664/jcsm.7984

8. Dalton L, Rapa E, Stein A. Protecting the psychological health of children through effective communication about COVID-19. Lancet Child Adolesc Health. 2020;4(5):346-347. doi:10.1016/S2352-4642(20)30097-3

9. Cao W, Fang Z, Hou G, et al. The psychological impact of the COVID-19 epidemic on college students in China. Psychiatry Res. 2020;287:112934. doi:10.1016/j.psychres.2020.112934

10. Soares-Silva L, Tavares-Silva C, Fonseca-Gonçalves A, Maia LC. Presence of oral habits and their association with the trait of anxiety in pediatric patients with possible sleep bruxism. J Indian Soc Pedod Prev Dent. 2019;37(3):245-250. doi:10.4103/JISPPD.JISPPD_272_18 
11. Direktör C, Serin NB. Psychometric properties of Spence Children's Anxiety Scale (SCAS). EURASIA J Math Sci Tech Ed. 2017;13(10):6725-6736. doi:10.12973/ejmste/78194

12. Li W, Yang Y, Liu ZH, et al. Progression of mental health services during the COVID-19 outbreak in China. Int J Biol Sci. 2020;16(10):1732-1738. doi:10.7150/ijbs.45120

13. Section II (Diagnostic Criteria and Codes): Anxiety Disorders. In: American Psychiatric Association. Diagnostic and Statistical Manual of Mental Disorders: DSM-5. $5^{\text {th }}$ ed. Washington, D.C. American Psychiatric Association Publishing; 2013. doi:10.1176/ appi.books.9780890425596

14. Prime $H$, Wade $M$, Browne DT. Risk and resilience in family wellbeing during the COVID-19 pandemic. Am Psychol. 2020;75(5):631-643. doi:10.1037/amp0000660

15. Hakan S. Study of adaptation of the Preschool Anxiety's Scale in children to Turkish. Int Educ Stud. 2020;13(9):82-95. doi:10.5539/ ies.v13n9p82

16. Spence $\mathrm{SH}$, Rapee $\mathrm{R}, \mathrm{McD}$ onald $\mathrm{C}$, Ingram $\mathrm{M}$. The structure of anxiety symptoms among preschoolers. Behav Res Ther. 2001;39(11):1293-1316. doi:10.1016/s0005-7967(00)00098-x

17. Edwards SL, Rapee RM, Kennedy SJ, Spence SH. The assessment of anxiety symptoms in preschool-aged children: The revised Preschool Anxiety Scale. J Clin Child Adolesc Psychol. 2010;39(3):400-409. doi:10.1080/15374411003691701

18. Jiao WY, Wang LN, Liu J, et al. Behavioral and emotional disorders in children during the COVID-19 epidemic. J Pediatr. 2020;221:264-266.e1. doi:10.1016/j.jpeds.2020.03.013

19. Pisano L, Galimi D, Cerniglia L. A qualitative report on exploratory data on the possible emotional/behavioral correlates of Covid-19 lockdown in 4-10 years children in Italy. PsyArXiv. 2020. doi:10.31234/osf.io/stwbn

20. Hukkelberg S, Keles S, Ogden T, Hammerstrøm K. The relation between behavioral problems and social competence: A correlational metaanalysis. BMC Psychiatry. 2019;19(1):354. doi:10.1186/s12888-019-2343-9

21. Knafo A, Plomin R. Parental discipline and affection and children's prosocial behavior: Genetic and environmental links. J Pers Soc Psychol. 2006;90(1):147-164. doi:10.1037/0022-3514.90.1.147

22. Orengul AC, Tarakcioglu MC, Gormez V, et al. Duration of breastfeeding, bottle-feeding, and parafunctional oral habits in relation to anxiety disorders among children. Breastfeed Med. 2019;14(1):57-62. doi:10.1089/bfm.2018.0013

23. Grippaudo C, Paolantonio EG, Antonini G, Saulle R, La Torre G, Deli R. Association between oral habits, mouth breathing and malocclusion. Acta Otorhinolaryngol Ital. 2016;36(5):386-394. doi:10.14639/0392-100X-770

24. Mohlin B, Westerlund A, Ransjö M, Kurol J. Chapter 21: Occlusal development, malocculsions, and preventive and interceptive orthodontics. In: Koch G, Poulsen S, Espelid I, Haubek D, eds. Pediatric Dentistry - A Clinical Approach. $3^{\text {th }}$ ed. Hoboken, NJ: Wiley-Blackwell; 2017:291-308.

25. Leme M, Barbosa T, Castelo P, Gavião MB. Associations between psychological factors and the presence of deleterious oral habits in children and adolescents. J Clin Pediatr Dent. 2014;38(4):313-317. doi:10.17796/jcpd.38.4.c48238322205466w

26. Foster LG. Nervous habits and stereotyped behaviors in preschool children. J Am Acad Child Adolesc Psychiatry. 1998;37(7):711-717. doi:10.1097/00004583-199807000-00010

27. Agarwal SS, Sharma M, Nehra K, Jayan B, Poonia A, Bhattal H. Validation of association between breastfeeding duration, facial profile, occlusion, and spacing: A cross-sectional study. Int J Clin Pediatr Dent. 2016;9(2):162-166. doi:10.5005/jp-journals-10005-1356

28. Saccomanno S, Antonini G, D'Alatri L, D'Angelantonio M, Fiorita A, Deli R. Causal relationship between malocclusion and ora muscles dysfunction: A model of approach. Eur J Paediatr Dent. 2012;13(4):321-323. PMID:23270292. 